\title{
Factors Affecting Ventilatory Function in the Child with Asthma
}

\author{
M. H. BUSTON* \\ From the Department of Child Health, Alder Hey Children's Hospital, Liverpool
}

\begin{abstract}
Exacerbations of asthma in children are often attributed to events producing stress or excitement, climatic changes, and infections; Peshkin (1959) showed that a marked clinical improvement often occurred on removing a child from his home environment. Purcell (1963), interviewing 20 asthmatic children described as rapidly remitting on withdrawal from their home environment, found that 15 of them reported as a trigger factor emotional arousal of an unpleasant nature, such as episodes of interpersonal conflict with members of their immediate family. Dekker and Groen (1956) demonstrated changes in vital capacity in response to exposure to stimuli which had a psychological effect on their subjects.
\end{abstract}

Various investigations have been made to determine the relation between climatic changes and asthma. Newell and Swafford (1963) found that attacks of asthma in children were not nearly as conspicuously related to wind speed and direction as were those in adults, as judged by the number of visits to the local emergency room, while Greenburg, Field, Reed, and Erhardt (1962) noticed no increase in the number of visits to asthma clinics during a period of high pollen pollution in New York City. Peshkin (1959) noted that children admitted to the National Home for Asthmatic Children at Denver, Colorado, did as well when they came from a nearby area as from more remote areas and that climate appeared to play a negligible role in the eventual therapeutic results achieved.

In this investigation an attempt was made to assess the relative importance of various environmental factors in groups of asthmatic children using measurements of the forced expiration volume in one second $\left(\mathrm{FEV}_{1}\right)$ as an objective measurement in addition to clinical observation.

The long-term effect of breathing exercises was also investigated. Several studies in which respira-

Received February 8, 1966.

* Present address: Birch Hill Hospital, Rochdale. tory function tests have been used to assess the effect of breathing exercises in patients with emphysema or asthma and bronchitis have been reported, including those of $\mathrm{McNeill}$ and McKenzie (1955), Miller (1954), Sinclair (1955), Becklake, McGregor, Goldman, and Braudo (1954), and Campbell and Friend (1955), but usually the benefit obtained does not appear to have been great. Scherr and Frankel (1958), investigating the longterm effect of breathing exercises combined with physical exercise in 25 asthmatic children, found some improvement clinically and in pulmonary function, but felt that these were primarily due to 'enlightenment of the child and parents concerning bronchial asthma which resulted in better cooperation with the physician and his treatment'.

In a preliminary investigation of the immediate effects of breathing exercises, 8 asthmatic children aged 7 to 14 years attending the hospital Physiotherapy Department were tested before and after exercise sessions, some children on several occasions; the exercises used were based on those recommended by the Asthma Research Council (1956) with some general physical exercise in addition. When the pre-exercise value was compared with values obtained immediately after and 5 and 10 minutes after the end of the session, it was found that no change or a slight fall in $\mathrm{FEV}_{1}$ occurred more often than a rise. It was then decided to investigate the effect of physical exercise and breathing exercises separately, the former being found to produce characteristic changes in $\mathrm{FEV}_{1}$ (Jones, Buston, and Wharton, 1962).

\section{Material and Method}

Included in the study were 18 asthmatic children between the ages of 7 and 15 years who were living at a residential special school (Group A). They were seen twice weekly on Mondays and Fridays at about 5 p.m., 10 of them during 3 consecutive terms and 8 during 2 consecutive terms.

In addition, 10 children between the ages of 10 and 16 years living at another convalescent home and school 
were seen 2 or 3 times weekly during the school term over a period of 6 months (Group B), and 2 children aged 13 living in a country hospital were seen 3 to 5 times weekly intermittently during a 5-month period (Group C).

The children in Group A were seen as early in each term as possible, within a day or two of their return to school.

At each visit a note was made of any symptoms or clinical signs of bronchoconstriction, of any upper respiratory tract infections, and of any events of interest or importance to the children, such as the parental visits which occurred for about two hours at alternate weekends in Groups A and B, school functions and excursions, and dental or hospital out-patient appointments, etc., which had occurred in the previous few days or were imminent.

From Group A 10 children were tested during an exciting film on one occasion and, on another, 5 children were tested immediately before and after an interschool football match, and also 5 and 10 minutes after the end of the match.

Of the children in Group A, 11 were visited once at home towards the end of their summer holidays, when a note was made of their symptoms and signs and their $\mathrm{FEV}_{1}$ was measured.

Daily maximum and minimum temperature readings were obtained from sites near the schools over a period of a year in Group A, and over 14 weeks in Groups B and C. Daily maximum and minimum humidity readings for Group A, and midday humidity readings for Groups $B$ and $C$, were obtained for the same periods.

Tests of ventilatory function were made using a modified Gaensler spirometer (Gaensler, 1951) which recorded the forced expiratory volume in one second; the instrument was calibrated at each visit by the method described by McKerrow, McDermott, and Gilson (1960), the results being converted to body temperature and pressure saturated with water vapour. The predicted normal value for each child was estimated from the height, using the values obtained by Strang (1959).

A group of 17 asthmatic children were given a breathing exercise session consisting of general body relaxation and repeated slow expiration, without any physical exercise, for about 20 minutes, and $\mathrm{FEV}_{1}$ readings for each child were obtained immediately before and after the sessions and again after 10 minutes. In 6 children more frequent readings were obtained over periods ranging from 28-58 minutes after the end of the session.

One girl, aged 15 years, carried out breathing exercises for 20 minutes during an attack of asthma, $\mathrm{FEV}_{1}$ readings being obtained before and at intervals after the session.

Although the short-term effect of breathing exercises on the $F E V_{1}$ appeared to be very slight, it was decided to investigate their effect over a longer period in 17 children in Group A who were given regular breathing exercises twice daily on 6 or 7 days a week under the supervision of a Sister; the exercises consisted mainly of breathing and relaxation with small periods of jumping up and down on the spot. The children were divided into two groups. One group carried out the exercises during the first and third months of the spring term, and the other group during the second month; during the second term the groups were changed round, so that each group had 3 months on the exercises and 3 off. Unfortunately it was not possible to keep the composition of the groups exactly the same during the whole period; by alternating the groups it was hoped to eliminate the effects of climatic changes, exposure to infections, and other environmental factors which were observed concurrently. The FEV was measured twice weekly as previously described and a note made of any signs and symptoms. In assessing the effects of the breathing exercises, the mean of the FEV values (expressed as a percentage of the predicted normal value for each child) obtained during the last two weeks of the second and third months of each term was used; the values obtained during the first month were not used, because marked spontaneous changes were often taking place following the return to school from holiday.

\section{Results}

During the school terms, 6 of the 18 children in Group A, and 2 of the 10 children of Group B rarely had symptoms or signs of asthma, and their $\mathrm{FEV}_{1}$ levels were within 1 standard deviation of their predicted normal values. 6 children in Group A, and 6 in Group B had occasional mild attacks of wheezing, and usually had $\mathrm{FEV}_{1}$ levels 2 standard deviations or more below their predicted normal values; expiratory rhonchi were heard sometimes on auscultation, but these children were able to participate fully in school activities.

Four children in Group A, 1 in Group B, and 1 in Group $C$ nearly always had signs and symptoms, and difficulty in keeping up with school activities. Their $\mathrm{FEV}_{1}$ readings tended to fluctuate widely between moderate and rather low levels. 2 children in Group A, 1 in Group B, and 1 in Group C were severely affected; they were very limited in their activities and usually had very low $\mathrm{FEV}_{1}$ levels and marked bronchospasm sometimes associated with transient cyanosis. 3 of these children died during or shortly after the observation period, i.e. both the children in Group C and one child in Group B who had symptoms of moderate severity during the school terms: 2 of these deaths were known to have been associated with chest infections.

The most potent of the various factors investigated was the effect of the change from home environment to that of school and vice versa. Table I shows the change in $\mathrm{FEV}_{1}$ seen during the first one to three weeks of each term in children in Group A, expressed as the difference between the first reading of the term and the point at which a relatively steady level in $\mathrm{FEV}_{1}$ values was reached subsequently. The majority of the children showed a rise in $\mathrm{FEV}_{1}$ at the beginning of each term.

Conversely, the reverse changes were demonstrated in 7 of 11 children in Group A who were visited 


\section{TABLE I}

Changes in FEV $V_{1}$ Values (expressed as a percentage of the predicted normal value) at the Beginning of Each Term, in 18 Children

\begin{tabular}{|c|c|c|c|c|c|c|}
\hline & & & 1st Term (13 subjects) & 2nd Term (14 subjects) & 3rd Term (16 subjects) & Mean (3 terms) \\
\hline $\begin{array}{l}\text { Range } \\
\text { Mean ... }\end{array}$ & & $\begin{array}{l}\cdots \\
\cdots\end{array}$ & $\begin{array}{c}-24 \cdot 9 \text { to }+75 \cdot 3 \\
+20 \cdot 4\end{array}$ & $\begin{array}{c}-2 \cdot 5 \text { to }+53 \cdot 7 \\
+23 \cdot 2\end{array}$ & $\begin{array}{c}-49 \cdot 7 \text { to }+64 \cdot 7 \\
+13 \cdot 2\end{array}$ & $+18 \cdot 9$ \\
\hline
\end{tabular}

towards the end of the summer holidays; in 9 there was a history of wheezing, sometimes starting a day or two after their return home, and in 7 the holiday readings were significantly below those of the last four weeks of the preceding term (Table II).

Upper respiratory infections which were not followed by a cough or bronchitis were only occasionally associated with decreased ventilatory function in Groups A and B. Excluding 5 children in Group A and 2 in Group B who were continuously wheezy, 47 upper respiratory infections occurred during the observation period in Group $A$ and 8 in Group B, but these were associated with only 4 episodes of wheezing in 4 children in Group $A$ and 3 episodes in 3 children in Group B. Changes in the FEV ${ }_{1}$ levels were usually transient and slight unless the infection was followed by a cough or bronchitis.

Parental visits. Although a history of wheezing on the day of a parent's visit was sometimes obtained, the effect was not prolonged. The mean $\mathrm{FEV}_{1}$ values obtained for visiting weekends was very similar to that obtained for non-visiting weekends in Group $A$, and there was not a greater number of unusually low readings when visiting Fridays and Mondays were compared with nonvisiting Fridays and Mondays.

The mean difference, expressed as a percentage of the predicted normal values, between visiting and non-visiting weekends in 11 children tested over a period of two terms was only $2.5 \%$ (range $0-4 \%$ ) and in 7 other children tested over 3 terms it was $3.3 \%$ (range $0-5 \%$ ).

Events. On very few occasions did any of the events that might have been expected to produce excitement or stress, such as school functions or excursions, produce sustained signs or symptoms as judged by twice weekly examination and testing, though in Group A a visit to the seaside was associated with wheezing and a $\mathrm{FEV}_{1}$ lower than usual in 5 of 15 children seen the day after the visit.

The 10 children in Group A who were tested during an exciting film showed no lowering of their $\mathrm{FEV}_{1}$ readings and no unusual signs of bronchoconstriction, though several expressed annoyance at being disturbed. None of the 5 children tested before the interschool football match showed a change in $\mathrm{FEV}_{1}$ when compared with the values obtained the previous evening or when retested immediately after the end of the match, and 5 and 10 minutes later.

Weather. In all groups there appeared to be no definite correlation between $\mathrm{FEV}_{1}$ readings, or clinical signs and fluctuations in the temperature and humidity, or gross changes in the weather, even when these were marked over a period of a few days. It was found in Group A, however, using the 'median pairs' test, that 5 of 18 children had a significantly greater number of high $\mathrm{FEV}_{1}$ values on days on

TABLE II

Comparison Between Term and Holiday FEV Values in 11 Children from Group $A$ Visited at Home

\begin{tabular}{|c|c|c|c|c|}
\hline Child & $\begin{array}{l}\text { Predicted Normal } \\
\text { Value (1.) }\end{array}$ & $\begin{array}{c}\text { Mean and Range of FEV } \mathrm{FE}_{1} \\
\text { Last } 4 \text { Weeks of Summer Term (1.) }\end{array}$ & Holiday FEVs (1.) & Significance \\
\hline $\begin{array}{l}1 \\
2 \\
3 \\
4 \\
5 \\
6\end{array}$ & $\begin{array}{l}2 \cdot 75 \\
1 \cdot 43 \\
3 \cdot 30 \\
2 \cdot 23 \\
1 \cdot 85 \\
2 \cdot 75\end{array}$ & $\begin{array}{l}2 \cdot 38(2 \cdot 17-2 \cdot 55) \\
1 \cdot 10(1 \cdot 00-1 \cdot 17) \\
2 \cdot 28(2 \cdot 12-2 \cdot 46) \\
1 \cdot 68(1 \cdot 31-2 \cdot 00) \\
1 \cdot 65(1 \cdot 48-1 \cdot 84) \\
1 \cdot 81(1 \cdot 71-1 \cdot 87)\end{array}$ & $\begin{array}{l}2 \cdot 03 \\
0 \cdot 33 \\
1 \cdot 38 \\
0 \cdot 52 \\
0 \cdot 41 \\
0 \cdot 48\end{array}$ & $\begin{array}{l}\mathbf{p}<\mathbf{0 . 0 5} \\
\mathbf{p}<\mathbf{0 . 0 5} \\
\mathbf{p}<\mathbf{0 . 0 5} \\
\mathbf{p}<\mathbf{0 . 0 5} \\
\mathbf{p}<\mathbf{0 . 0 5} \\
\mathbf{p}<\mathbf{0 . 0 5}\end{array}$ \\
\hline $\begin{array}{r}7 \\
8 \\
9 \\
10 \\
11\end{array}$ & $\begin{array}{l}1 \cdot 65 \\
2 \cdot 35 \\
2 \cdot 40 \\
2 \cdot 05 \\
2 \cdot 92\end{array}$ & $\begin{array}{l}1 \cdot 13(0 \cdot 96-1 \cdot 25) \\
1 \cdot 36(1 \cdot 00-1 \cdot 82) \\
0 \cdot 96(0 \cdot 59-1 \cdot 18) \\
1 \cdot 62(1 \cdot 44-1 \cdot 74) \\
0 \cdot 74(0 \cdot 23-1 \cdot 55)\end{array}$ & $\begin{array}{l}0 \cdot 89 \\
0 \cdot 83 \\
0 \cdot 59 \\
1 \cdot 71 \\
0 \cdot 29\end{array}$ & $\begin{array}{l}p<0.05 \\
p>0.05 \\
p=0.05 \\
p>0.05 \\
p>0.05\end{array}$ \\
\hline
\end{tabular}




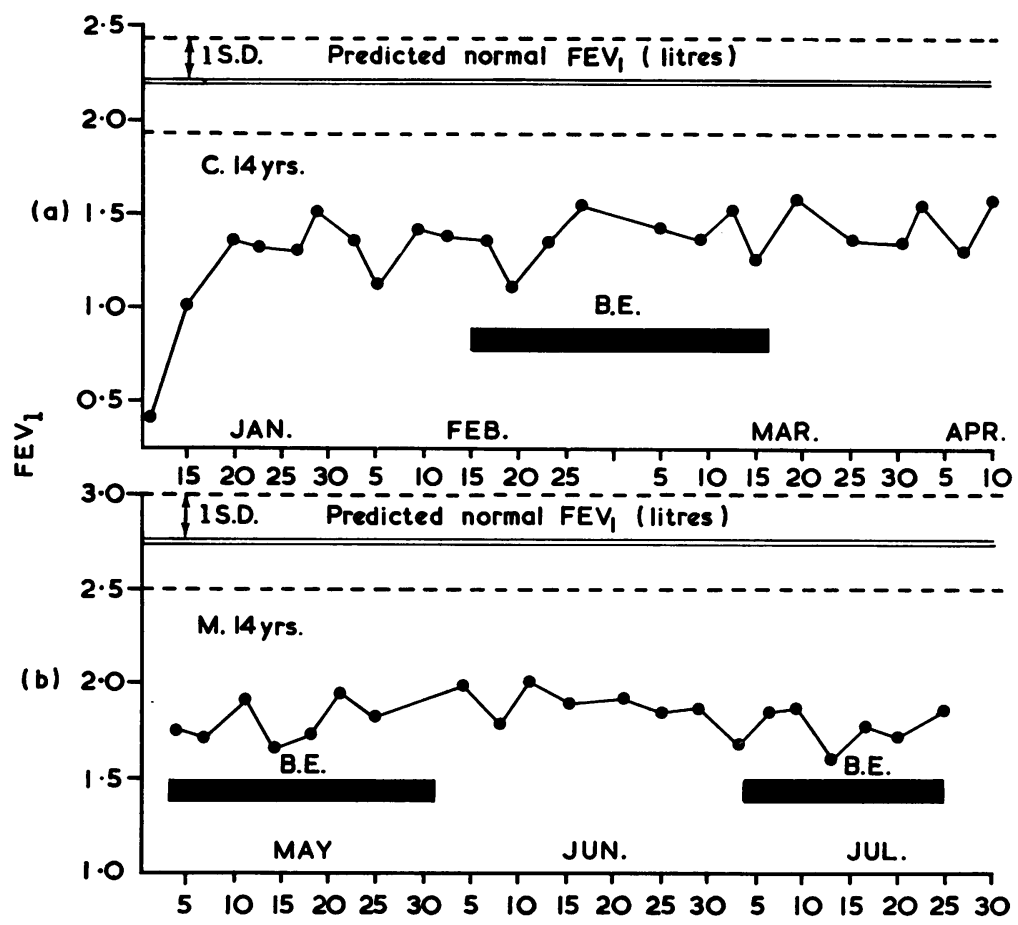

FIG. 1a and b.-Effect of breathing exercises $(B E)$ on FEV, in 2 children. The double line in each case is the predicted normal $F E V_{1}$, and the broken lines are $\pm 1 S D$.

which the temperature rose over $60^{\circ} \mathrm{F}$. $\left(15 \cdot 6^{\circ} \mathrm{C}\right.$. $)$ compared with days on which the temperature did not exceed $50^{\circ}$ F. $\left(10^{\circ}\right.$ C. $)$, and 4 children had a significantly greater number of low $\mathrm{FEV}_{1}$ values when the humidity exceeded $70 \%$ saturation for 24 hours compared with days in which the humidity fell below $70 \%$ saturation.

\section{Breathing exercises}

Immediate effect. Immediately after a session of breathing exercises, unassociated with physical exercise, carried out by the group of 17 asthmatic children, 11 showed a slight fall in $\mathrm{FEV}_{1}$ compared with the pre-exercise level, 4 stayed at the same level, and 2 showed a slight rise-not sufficient to be of therapeutic value; 10 minutes later the $\mathrm{FEV}_{1}$ readings of 9 children were still below their pre-exercise value, and those of $8 \mathrm{had}$ risen very slightly above it, but again by an amount unlikely to be of much benefit. A similar lack of marked change was seen when a more detailed follow-up was carried out in 6 children over a period ranging from 28 to 58 minutes.

The 15-year-old girl who was given breathing exercises for 20 minutes during an attack of asthma showed no increase in $\mathrm{FEV}_{1}$ and no relief of symptoms.

Long-term effect. It became apparent that very little change in $\mathrm{FEV}_{1}$ was produced when the periods during which the children were given breathing exercises were compared with the periods when they were not; comparing the mean $\mathrm{FEV}_{1}$ values (expressed as a percentage of the predicted normal value) obtained during the last two weeks of each monthly period, when the children changed from the month off breathing exercises to the month on, 6 children showed a rise in $\mathrm{FEV}_{1}$ (mean $+4.7 \%$, range $+1 \cdot 2 \%$ to $+8 \%$ ) and 6 a fall (mean $4.8 \%$, range $-1.2 \%$ to $-11 \%$ ). When they changed from a month on breathing exercises to a month off, 8 children showed a rise in $\mathrm{FEV}_{1}$ (mean $+5 \cdot 3 \%$, range $+1 \%$ to $+11 \cdot 5 \%$ ) and 7 a fall (mean $-5 \cdot 6 \%$, range $-0 \cdot 7 \%$ to $-11 \cdot 1 \%$ ); one child showing no change. Fig. 1 shows examples of the graphs of $\mathrm{FEV}_{1}$ values obtained in two children during a term in which they were given breathing exercises. 


\section{Discussion}

In these groups of asthmatic children the most important changes in $\mathrm{FEV}_{1}$ and in the incidence of wheezing were noted when the children were moved from the school to the home environment and vice versa, confirming Peshkin's observations of the beneficial effect of removing some asthmatic children from their home environment. Various events and parental visits occurring during the school term usually did not produce marked signs or symptoms, and if these did occur they were not prolonged.

The minor effects of weather change noted by other investigators were also confirmed, gross changes in weather occurring over a few days making little apparent difference, and the correlation between higher $\mathrm{FEV}_{1}$ values with higher temperatures and lower $\mathrm{FEV}_{1}$ values with higher humidity occurred only in a minority of the children.

Upper respiratory infections unaccompanied by bronchitis also appeared to have little effect; the potential danger of respiratory infections, however, is indicated by the fact that of the 3 children in the series who died during or within 3 months of the observation periods, 2 were associated with infection. 2 other children, who were observed briefly and not included in the above groups, also died, one having evidence of extensive chronic pulmonary infection.

These findings suggest that in the majority of these children, who had been admitted to residential accommodation because of the severity of their asthma while they were at home, some factors in the home environment were contributing to their symptoms. It was not possible to assess adequately what these factors were, but it seemed likely that in some cases at least interpersonal relationships within the family were important.

Previous investigations indicating the lack of effect of breathing exercises on ventilatory function were confirmed. Little objective improvement in the degree of bronchial constriction was observed either immediately after a session or over a period of a month. While breathing exercises may have some value in correcting posture, in producing general relaxation, and in making a child feel one of a group rather than an isolated handicapped child, it seems unlikely that they can significantly diminish the hyperinflation and barrel-shaped chest associated with broncho-constriction.

\section{Summary}

Observations were made on 30 asthmatic children living away from home to ascertain the relative importance of various factors in causing asthmatic attacks, clinical observations being combined with regular recordings of the forced expiratory volume in one second. The most potent of the factors investigated was the effect of the change of environment from home to school and vice versa, other factors such as weather changes, events of interest and importance to the children, and upper respiratory infections having much less effect.

I am very grateful to Dr. G. S. Robertson, to Dr. L. A. McAfee and to the Paediatricians of Alder Hey Children's Hospital and the Royal Liverpool Children's Hospital for allowing me to study the patients under their care, and to Dr. R. S. Jones for constant help in the planning and conduct of the investigation.

\section{REPERENCES}

Asthma Research Council (1956). Exercises for Asthma and 'Emphysema', 9th ed., ed. J. L. Livingstone and J. M. W. Reed. A.R.C., London.

Becklake, M. R., McGregor, M., Goldman, H. I., and Braudo, J. L. (1954). A study of the effects of physiotherapy in chronic hypertrophic emphysema using lung function tests. Dis. Chest, 26, 180.

Campbell, E. J. M., and Friend, J. (1955). Action of breathing exercises in pulmonary emphysema. Lancet, 1, 325.

Dekker, E., and Groen, J. (1956). Reproducible psychogenic attacks of asthma. A laboratory study. f. psychosom. Res., 1, 58.

Gaensler, E. A. (1951). An instrument for dynamic vital capacity measurements. Science, 114, 444.

Greenburg, L., Field, F., Reed, J. I., and Erhardt, C. L. (1962). Air pollution and morbidity in New York City. F. Amer. med. Ass., $182,161$.

Jones, R. S., Buston, M. H., and Wharton, M. J. (1962). The effect of exercise on ventilatory function in the child with asthma. Brit. F. Dis. Chest, 56, 78.

McKerrow, C. B., McDermott, M., and Gilson, J. C. (1960). A spirometer for measuring the forced expiratory volume with a simple calibrating device. Lancet, 1, 149.

McNeill, R. S., and McKenzie, J. M. (1955). An assessment of the value of breathing exercises in chronic bronchitis and asthma. Thorax, 10, 250.

Miller, W. F. (1954). A physiologic evaluation of the effects of diaphragmatic breathing training in patients with chronic pulmonary emphysema. Amer. $\mathcal{F}$. Med., 17, 471.

Newell, G. R., Jr., and Swafford, L. I. (1963). Epidemiology of asthma in children with particular reference to wind speed and wind direction. Pediatrics, 31, 134.

Peshkin, M. M. (1959). Intractible asthma of childhood. Rehabilitation at the institutional level with a follow-up of 150 cases. Int. Arch. Allergy, 15, 91.

Purcell, K. (1963). Distinctions between subgroups of asthmatic children. Children's perceptions of events associated with asthma. Pediatrics, 31, 486.

Scherr, M. S., and Frankel, L. (1958). Physical conditioning program for asthmatic children. F. Amer. med. Ass., 168, 1996

Sinclair, J. D. (1955). The effect of breathing exercises in pulmonary emphysema. Thorax, 10, 246.

Strang, L. B. (1959). The ventilatory capacity of normal children. ibid., 14, 305. 